\title{
Fabrication of Feeding Plate in Cleft Palate Patient: A Case Report
}

\author{
Tulsi Gajendra Lodhi ${ }^{1}$ Surendra Kumar Bhagwatrao Patil ${ }^{1}$ Surendra Kumar Kaluram Bahetwar ${ }^{2}$ \\ Aparna Balkrishna Sharma ${ }^{1}$ Nupur Suresh Ninawe ${ }^{2}$ Arti Rameshwar Dolas²
}

\footnotetext{
${ }^{1}$ Department of Plastic, Reconstructive \& Maxillofacial Surgery, Government Medical College and Hospital, Nagpur, Maharashtra, India

2Department of Pedodontics and Preventive Dentistry, Government Dental College and Hospital, Nagpur, Maharashtra, India
}

\begin{abstract}
Address for correspondence Surendra Kumar Kaluram Bahetwar, BDS, MDS, Department of Pedodontics and Preventive Dentistry, Government Dental College and Hospital, Nagpur 440003, Maharashtra, India (e-mail: drsurendra.bahetwar@yahoo.com).
\end{abstract}

Dent J Adv Stud 2019;7:35-37
Abstract
Keywords
- cleft lip and cleft palate
- cleft lip
- cleft palate
- feeding plate

Cleft lip and palate is one of the most common congenital craniofacial malformations. It is associated with various problems such as difficulty in sucking, nasal regurgitation, hearing and speech problems, etc. Feeding is of primary and immediate concern for the growth of infants. In this case report, a 3-month-old female child diagnosed with Veau's class II cleft reported with the difficulty in sucking of milk and nasal regurgitation while feeding. To overcome this problem, a feeding plate was fabricated with simple impression method, which helped the infant feed and restore the proper weight required for cleft palate reconstructive surgery.

\section{Introduction}

Cleft lip and palate (CLP) is one of the most common congenital craniofacial defects. Cleft palate $(\mathrm{CP})$ is a fissure in the midline of the palate due to failure of the two sides to fuse in embryonic development. It is commonly associated with cleft lip (CL) and tooth malformation. ${ }^{1}$ Worldwide incidence of CLP is 1 in $600^{2}$ and prevalence is 6.64 per $10,000,{ }^{3}$ whereas the prevalence of CL with or without CP is 9.92 per 10,000 and $\mathrm{CL}$ alone is 3.28 per 10,000 . The approximate birth rate in India is estimated to be 24.5 million births per year, and the prevalence of cleft cases in that is between 27,000 and 33,000 per year. ${ }^{4}$

The ratio of $\mathrm{CL}$ in male to female is $2: 1$, whereas $\mathrm{CP}$ without $\mathrm{CL}$ is more common in females. ${ }^{5}$ This is due to 1 week later fusion of the palatine shelves in girls as compared with boys, resulting in higher occurrence of CP in girls. ${ }^{6}$ CLP may or may not be associated with various syndromes such as Pierre-Robin sequence, Stickler's syndrome, Di George syndrome, Treacher Collins malformation, trisomy 13 and 18, Apert's syndrome, and Waardenburg's syndrome. ${ }^{7}$

$\mathrm{CP}$ is associated with difficulty in sucking, nasal regurgitation while feeding, deficiency of facial growth, dental and aesthetic problems, velopharyngeal inadequacy resulting in

received

December 24, 2018

accepted after revision

January 9, 2019

published online

March 28, 2019 defective speech, and hearing and psychological problems. ${ }^{8}$ Among all the problems, feeding is an immediate concern in children born with cleft as it delays their normal growth. Also, this can be a major concern for infants who will be undergoing surgery to correct their cleft. CL or CP can be treated by reconstructive surgery that is performed in the first few months of life for $\mathrm{CL}$ and before 18 months for $\mathrm{CP}$. Therefore, for this period to overcome the problems of feeding, a feeding plate (FP) is recommended to the patient, which acts as a rigid platform against which the child can press the nipple to extract the milk.

It separates the oral cavity from the nasal cavity, which reduces the nasal regurgitation and creates a negative pressure required for sucking and thus shorten the time of feeding ${ }^{1,9}$ It prevents the lodgment of the tongue in the defect, ${ }^{10-12}$ which otherwise interferes with the spontaneous growth of palatal shelves toward the midline. It also helps in the development of the jaw by allowing the tongue to place in correct position and contributes in speech by performing its functional role. ${ }^{13}$ FP helps the CLP patient in restoring the proper weight, which is required for CLP reconstructive surgery. In this case report, fabrication of FP is explained by using simple impression technique and impression material that can be easily removed from the oral cavity in case of emergency. 


\section{Case Report}

A 3-month-old female child reported to the Department of Plastic, Reconstructive \& Maxillofacial Surgery, GMCH, Nagpur, with complaint of difficulty in sucking of milk and nasal regurgitation while feeding. The infant was the first child of the parents. The weight of the child at birth was $2 \mathrm{~kg}$, and it was observed that the weight did not increase due to inability to take oral feed. The mother had a full-term pregnancy, but the infant was delivered at home. The infant was diagnosed with cardiac problem since birth for which she was under observation of the pediatrician and cardiologist. Family history was not contributory except that the parents were of consanguineous marriage. On intraoral examination, cleft of hard and soft palate was seen (Veau's class II; - Fig. 1). To overcome the feeding problem, an FP was planned, which would act as a barrier between the nasal and oral cavity and also to prevent nasal regurgitation.

\section{Steps in Fabrication of Feeding Plate}

Impression making in CLP patient is a crucial and a challenging procedure due to limitation of the size of infant's oral cavity, variation in anatomy, and lack of cooperation of the infant to respond to commands while impression making procedure. ${ }^{14}$ In the literature, various types of impression materials such as alginate, ${ }^{12,13}$ low fusing compound, ${ }^{15}$ and elastomeric impression material ${ }^{8}$ have been suggested for making impression in cleft patient. Also, several positions such as prone, facedown, upright, and even upside-down positions have been reported in the literature for $\mathrm{CP}$ patient while impression making, to prevent the airway obstruction.

\section{Primary Impression}

In this case, the preliminary impression was made without any anesthesia or premedication with impression compound ( - Fig. 2 ) by supporting with the finger. Impression compound was chosen, as it has excellent tear resistance, and also it can be easily removed before it sets, in case of any emergency. During the procedure, to avoid aspiration by the infant, the patient was held with her face toward the floor and made to cry by tapping on his foot, to ensure a patent airway.

\section{Cast Preparation and Custom Tray Fabrication}

Primary cast was made with dental plaster. After the cast sets, a custom acrylic tray was fabricated on it and perforations were then made on the custom tray.

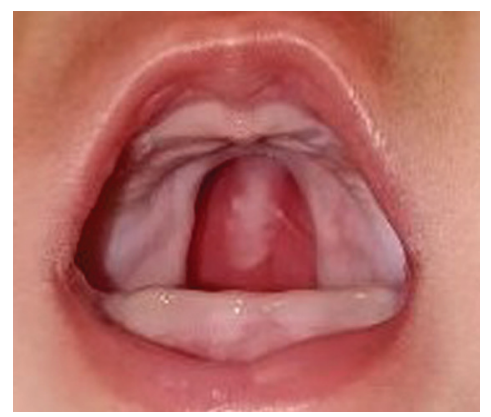

Fig. 1 Intraoral photograph showing Veau's class II cleft palate.

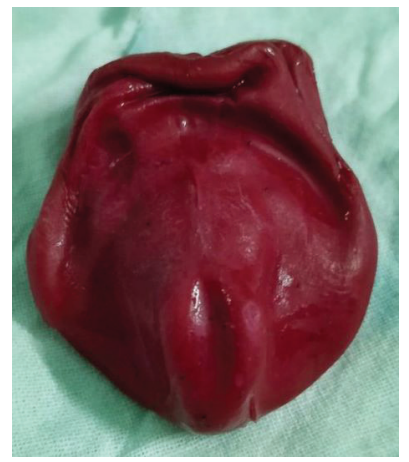

Fig. 2 Preliminary impression made with impression compound.

\section{Secondary Impression}

Secondary impression was made with medium body polyvinyl siloxane impression material, by loading on the adhesive-coated custom tray (-Fig. 3) and in the same position as mentioned earlier for primary impression. Elastomeric impression material has the advantage of accurate surface reproduction and also has a good tear resistance.

\section{Master Cast}

The obtained impression was poured in a type III dental stone. The master cast was then lubricated with separating media.

\section{Feeding Plate}

FP was prepared with cold cure acrylic resin and monomer by sprinkle on method. It was properly finished and polished to avoid impingement of soft tissue.

\section{Attachment of Dental Floss on Feeding Plate}

A floss was then attached on the FP ( $\boldsymbol{- F i g . 4}$ ) for easy removal of plate by parents in an accidental swallowing or in case of gagging.

FP was checked in the patient's mouth for any overextension and impingement of the soft tissue. After that, the mother was told to feed the infant. It was observed that the child was now successfully taking the feed with the FP in the mouth, without nasal regurgitation. All the instructions about the feeding technique, cleaning and maintenance of FP and maintenance of oral hygiene were explained to the parents. The patient was recalled after 24 hours to check for

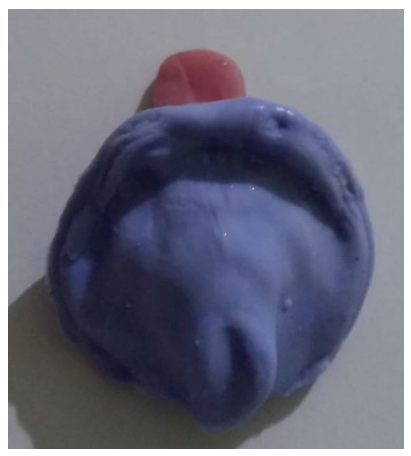

Fig. 3 Secondary impression made with medium-body elastomeric impression material. 


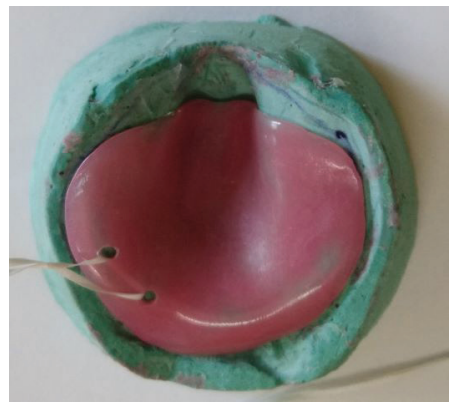

Fig. 4 Fabricated feeding plate with attached dental floss.

any discomfort or for any impingement of soft tissues. The patient was recalled again after 1 week for the same. The patient was then followed up after every 3 to 4 weeks, for the reduction in the border of the FP to accommodate the growing arches. The weight of the infant was also monitored on every visit. After every 3 months, a new FP was advised to accommodate the enlarged craniofacial sutures at growth.

\section{Discussion}

Treatment of CLP is a team work of the pediatrician, plastic surgeon, pedodontist, and prosthodontist. CL and CP are successfully treated by plastic and reconstructive surgery. However, till the surgery, to overcome the problems associated with the feeding and to restore the weight required for surgery, a temporary appliance known as FP is fabricated by the pedodontist or prosthodontist to break the vicious cycle of low weight due to which the patient becomes unfit for surgery. Fabrication of the FP is a challenge due to variation in anatomy of cleft, size of oral cavity, lack of cooperation, and chances of the infant to aspirate while impression making. Therefore, proper selection of impression material is necessary to reproduce accurate surface details and also can be easily handled and removed from the oral cavity, if any emergency exists. Along with this proper position of the infant is also important during impression making procedure.

\section{Conclusion}

The FP overcomes the hindrances which occur during the normal growth and development of a cleft patient and thus should be advised as early as possible after birth. It acts as an important tool for feeding, oral-facial development, development of palatal shelves, prevention of tongue distortion, nasal regurgitation and nasal septum irritation, and avoiding ear infections; it also prevents the expansion of anterior part of the maxilla, which helps the surgeon provide proper reconstructive treatment.

Conflict of Interest

None declared.

\section{References}

1 Oxford Concise Medical Dictionary. 8th ed. Oxford University Press:2010:208

2 Cooper ME, Stone RA, Liu Y, Hu DN, Melnick M, Marazita ML. Descriptive epidemiology of nonsyndromic cleft lip with or without cleft palate in Shanghai, China, from1980 to 1989. Cleft Palate Craniofac J 2000;37(3):274-280

3 Murray JC. Gene/environment causes of cleft lip and/or palate. Clin Genet 2002;61(4):248-256

4 Ghonmode SW, Kalaskar AR, Kalaskar RR, Chole R, Bhushan P, Ali FM. Vista of cleft lip and palate in India. Evolution of Medical and Dental Sciences. 2012;1(6):1102-1111

5 Watkins SE, Meyer RE, Strauss RP, Aylsworth AS. Classification, epidemiology, and genetics of orofacial clefts. Clin Plast Surg 2014;41(2):149-163

6 Jensen BL, Kreiborg S, Dahl E, Fogh-Andersen P. Cleft lip and palate in Denmark, 1976-1981: epidemiology, variability, and early somatic development. Cleft Palate J 1988;25(3):258-269

7 Chandna P, Adlakha VK, Singh N. Feeding obturator appliance for an infant with cleft lip and palate. J Indian Soc Pedod Prev Dent 2011;29(1):71-73

8 Rathee M, Hooda A, Tamarkar A, Yadav S. Role of feeding plate in cleft palate: case report and review of literature. Internet J Otorhinolaryngol 2010;12:1

9 Kogo M, Okada G, Ishii S, Shikata M, Iida S, Matsuya T. Breast feeding for cleft lip and palate patients, using the Hotz-type plate. Cleft Palate Craniofac J 1997;34(4):351-353

10 Goldberg WB, Ferguson FS, Miles RJ. Successful use of a feeding obturator for an infant with a cleft palate. Spec Care Dentist 1988;8(2):86-89

11 Samant A. A one-visit obturator technique for infants with cleft palate. J Oral Maxillofac Surg 1989;47(5):539-540

12 Oliver HT. Construction of orthodontic appliances for the treatment of newborn infants with clefts of the lip and palate. Am J Orthod 1969;56(5):468-473

13 Osuji OO. Preparation of feeding obturators for infants with cleft lip and palate. J Clin Pediatr Dent 1995;19(3):211-214

14 Ravichandra KS, Vijayaprasad KE, Vasa AA, Suzan S. A new technique of impression making for an obturator in cleft lip and palate patient. J Indian Soc Pedod Prev Dent 2010;28(4): 311-314

15 Muthu MS. Management of an infant with cleft lip and palate with phocomelia in dental practice. J Indian Soc Pedod Prev Dent 2000;18(4):141-143 